\title{
Globalization And Convergence-Divergence Debate: Strategic Perspectives For Emerging Markets
}

\author{
Vipin Gupta, (E-mail: gupta@management.wharton.upenn.edu), Wharton School, University of Pennsylvania \\ Jifu Wang, (E-mail: wangj@uhv.edu), University of Houston, Victoria
}

\begin{abstract}
Globalization calls for a strategic business model that supports creation and sustaining of competitive advantage internationally. Here, we highlight the significance of a transvergence perspective, which is a transformative reinterpretation and application of the indigenous cultural perspective. Two case studies of Chinese enterprises highlight the perspective.
\end{abstract}

\section{Introduction}

Globalization calls for a strategic business model that supports creation and sustaining of competitive advantage at an international level (Pfeiffer, Goodstein, \& Nolan, 1992). Strategic business model builds from the current situation to a vision of the desired future state, with a blueprint of the actual pathway. It unifies and translates domain selections, resources and capabilities, investment and collaboration vehicles, and timing and sequence of competitive moves, into a new profit model (Slywotsky \& Morrison, 1997), a sustainable growth model (Higgins, 1977), and a meaningful organizational identity (Albert \& Whetten, 1985).

The effects of globalization on strategic business models are both homogenizing ("convergence" school) as well as variety promoting ("divergence" school). The Convergence scholars (Pascale \& Maguire, 1980) hold that as the countries liberalize their markets, develop institutions, adopt modern technology, and achieve industrialization, the strategic business behavior would become similar because people will embrace common values with regard to economic activity and work-related behavior (England \& Lee, 1974; Kerr et al., 1964).

The Divergence scholars instead assert that national culture, not economic ideology or technological growth, is (and will continue to be) the dominant force in shaping the values, beliefs, and attitudes of managers within a country (Hofstede, 1980, Laurent, 1983). Many scholars believe in the functional equivalence (Child, 1981) - globalization is not about convergence to best practice, but rather about leveraging difference in an increasingly borderless world to gain differentiated positions and advantages (Guillén, 2000).

To bridge the differences between Convergence and Divergence schools, Ralston, Gustafson, Cheung, and Terpstra (1993) propose a middle ground using the term 'crossvergence' defined as a value set that was "in between" the values supported by the East and the West. Crossvergence suggests that the Asian organizations would develop a "hybrid" model -- blending the best elements of both their domestic and imported ideas (Abo, 1994).

While crossvergence offers a powerful perspective to integrate the twin forces of technological capability (associated with convergence) and cultural embeddedness (associated with divergence), it is not the only alternative. Sometimes the managers must integrate global models with their societal and organizational culture. In these situations, a distinct approach, that we term as 'transvergence', is needed. Transvergence may be defined as a formative change in the strategic modalities of an organization's business through a creative reinterpretation and reapplication of indigenous culture and emergent market and technological opportunities.

Readers with comments or questions are encouraged to contact the authors via email. 
This paper focuses on the question of how globalization influences the managerial choice among four alternatives for developing a competitive strategic business model. Our analysis is based on the case studies of two firms in People's Republic of China. We demonstrate that the firm's decisions are a function of their cultural embeddedness and technological capability.

Cultural Embeddedness: Cultural embeddedness is a term used by the geographers to refer to the common values and ties amongst firms and their constituencies (Suarez-Villa \& Rama, 1996).

Technological Capability: Technological capability refers to comprehensive knowledge about a broad spectrum of technological options, ranging from simple to high technologies, and the ability to evaluate and select technologies, to utilize, adapt, and improve them, and to further develop them (Hillebrand, Messner, \& Meyer-Stamer, 1994).

We next review the literature on the post-liberalization business models in People's Republic of China, and formulate an integrative framework that shows how cultural embeddedness and technological capability influence business models. Then, we present two case studies to demonstrate the framework, and discuss the implications of our findings.

\section{Impact of Globalization on Chinese Business Models}

The scholars agree that globalization makes managerial decisions about strategic business model very challenging, because of increased uncertainty, volatility, and competition (Brown \& Eisenhardt, 1998). The demands are even more challenging for an emerging economy, where the resources are constrained and the institutions also undergo substantive change as part of the globalization process. However, scholars differ on how to address these challenges. One way to identify these differing perspectives is to consider different categories of firms. In China, the firms can be broadly classified into four categories: state-owned (federal), township, foreign-invested, and private entrepreneurs. Scholars have suggested quite different responses for adaptation and different approaches for strategic business models for these four types of firms.

Several studies suggest that the strategic business models of the State-owned (federal) firms in China tend to have high levels of cultural embeddedness with an assigned mission to participate in the government's economic plan, but lack technological capability (Zhao, 1997). Their strategic business model has been based on a "divergent" Confucian-Communist ideology: exploiting the official guanxi to gain advantage in the open market. Hay, Morris, Liu and Yao (1994), for instance, analyzed responses of 351 directors of state-owned enterprises in China. Most applied official guanxi (using management skills) to gain favorable financial support and relied on unofficial guanxi (using social support) for other intermediate inputs. About half of them had investments in other enterprises, with a view to secure materials $(21.1 \%)$, pursue inter-firm technological cooperation $(6.8 \%)$, expand production capacity $(6.3 \%)$, increase profits through further loans (6.3\%), and sales promotion (4.0\%).

Another type of Chinese enterprises is the Township or collective enterprises - typically owned by the local governments and communities. Studies suggest that township enterprises also tend to have high cultural embeddedness because of their social mandate, and being affiliated with local governments protects them from government interference (Nee, 1992). In addition, these townships sell in competitive markets, so unlike state-owned enterprises they face "hard budget constraints" that encourage efficiency and technological capability (Kornai, 1989). They have combined a "collective orientation" with a "strong entrepreneurial spirit" (Bruton et. al., 2000). They account for more than $40 \%$ of the industrial output of China and have had some of the greatest financial success of domestic firms within China (Bruton et. al., 2000).

The third type of firms - the foreign-invested firms - has become popular after liberalization. Several studies show that foreign-invested firms lack cultural embeddedness, but have high levels of technological capability (Luo, 1998). About 80\% of foreign direct investment in China took the form of joint ventures (Wong et. al., 1999). Glaister and Wang (1993) found that the Chinese partners were sought for accessing complementary inputs such as links with major buyers and ability to negotiate with the government officers, and an established marketing and distribution system. Though Chinese partners do lack hands-on experience with technology, foreign expatriates help 
them gain technical and managerial expertise, by establishing quality control in both services and materials. A few foreign ventures that been particularly successful (e.g. Walmart) are the ones building guanxi with the government, employing native managers, and developing their own distribution system using Chinese themes (Wong et. al., 1999). Luo (1997) found that guanxi-based marketing and credit granting had a positive impact on profitability, asset turnover, and domestic sales growth of foreign-invested enterprises. Thus, foreign-invested firms have tended to "converge" to a typical Anglo approach, with a functional adaptation of their strategic business model to the local cultures.

The final type includes private enterprises, which are a relatively new phenomenon in the Chinese society that traditionally looked down upon private wealth (Tsang, 1996). Research indicates that private enterprises tend to lack cultural embeddedness as well as technological capability (Tsang, 1996). Using interviews with executives in Chinese state-owned, township, and private enterprises, Xin \& Pearce (1996) found that private enterprise executives tended to attach greatest significance to their personal business connections and to building official government connections, because they were most lacking in institutional support. Lau \& Busenitz (2001) analyzed data from the private enterprises in China, using a 1991 representative national sample of 2,878 enterprises. The findings showed that business owners' perceived difficulties in bank borrowing positively influenced intention to form cooperative arrangements with foreign and state-owned firms for expansion. Tsang (1996) elucidated that the private enterprises lack legitimacy under communist ideology. The entrepreneurs seek to co-opt senior local cadres of the government in the state-owned firms to run their business more smoothly. Further, they seek to co-opt foreign-owned firms to learn modern management techniques and advanced technology, and alliance with them can secure fiscal and other incentives. Thus, private enterprises have pursued a cross-vergence between the Chinese and the Anglo model, trying to legitimatize their home operations and to build technological advantages.

\subsection{Summary}

State-owned and township enterprises tend to demonstrate high levels of cultural embeddedness - because of their deep roots in the communist ideology. However, township enterprises differ from the state-owned enterprises, in that the former have to survive using meager resources of the local governments and face competition from the enterprises in other local communities. They have adopted rather innovative approaches including collaborations with the overseas Chinese community for buy-back arrangements. The state-owned firms, on the other hand, have "diverged" to a typical Chinese model of relying on official guanxi. In contrast, foreign-invested and private enterprises tend to demonstrate low levels of cultural embeddedness - because of the traditional Confucian aversion to the private business enterprise. The foreign-invested firms enjoy higher levels of technological capability, because of the support from their foreign parents, and have "converged" to a quasi-Anglo strategic business model.

\section{An Integrative Framework}

The presence as well as absence of cultural embeddedness and technological capability has an important influence on the strategic business model of the emerging markets under globalization. When cultural embeddedness is low, the acceptance of foreign elements tends to be higher because of the weaker cultural ties. If the firms have high technological capability, they have a better absorptive capacity for the foreign know-how and can adopt the global best practice model for gaining credibility in the international markets. This is likely to contribute to a "convergence" to the dominant global model, i.e. Anglo model.

However, when the firms have low technological capability, they can compete at best using global knowhow that is widely available and that too with high costs of adoption because of their limited absorptive capacity. Therefore, these firms must add some compensating home-based advantages, which is likely to result into a "crossvergence" or firm-specific hybrid between domestic and foreign elements.

In contrast, when cultural embeddedness is high, then foreign elements tend not to be readily accepted. If the firms lack technological capability, they may still survive or flourish by leveraging their local relationships, which is likely to generate "divergence" in their business model oriented towards local culture. But if they have strong technological capability, then they are likely to adopt a discovery-driven "trans-vergence" approach to identi- 
fy and exploit emergent entrepreneurial opportunities locally or globally, and thus to better respond to their cultural mandates also.

Next, we illustrate the hypothesized framework using the cases of two Chinese enterprises, using direct interviews with the enterprise executives and supplemental media information. The enterprises in China have experienced great change in their operating environment, ranging from changes in consumer and industrial markets, finance system, labor market, government regulations, competition, and performance management (Sun, 2002). Many of the smaller enterprises have been merged, taken over, or declared bankrupt (Guo, 2001). We hypothesize that the Chinese enterprises would seek to compete by adopting a strategic business model consistent with their levels of cultural embeddedness and technological capability.

\subsection{Case I: C\&C - High Cultural Embeddedness, Low Technological Capability}

In 1990, Chongquing (C\&C) was in 10 million yuan debt and faced bankruptcy. Its technology was poor $;$; quality was low, and market focus was low-end. CEO Zhang realized that change wais a necessity, not an option. His revival project called for upgrading the outdated factory, setting up a national sales network, and expanding sales overseas. However, C\&C was not listed in China's Eighth Five-Year National Plan (1990-1995) as a technically qualified enterprise, and so he had to obtain a special approval from the Central Ministry for his project.

After the banks turned down funding for this risky project, Zhao persisted for help from the State, and finally got US $\$ 4$ million from the State reserves. Zhang recognized that these funds are insufficient in making $C \& C$ a leader in its sector, and sought a foreign joint venture partner. However, getting an international partner was not easy, since most of them saw investment into C\&C's outdated operations equivalent to" throwing money in the fire."

Eventually, Zhang met Zhaofeng Li, President of Hong Kong-based Zhaofeng Ceramics Group, whose vision was to become king of the Chinese ceramics business, at a local ceramics exhibition. After an initial partnership, in 1993, a \$5 million joint venture, Chongqing Zhaofeng Ceramics Co. Ltd., was established with 75\% Chongquing and $25 \%$ Zhaofeng ownership. The venture's charter focused on "employing the best people, using the best manufacturing facilities, manufacturing the best products and creating the best organization". The goal was to launch a facility that would be an exemplar for next 20 years.

With the help of Zhaofeng, C\&C decided to import state-of-the-art and automated German manufacturing equipment. It also bought, from the Germany Ceramic Research Center, a ceramic formula to use Chinese raw materials that met the standards of German five-star hotels. In addition, it obtained 30 sets of blue prints of the best German designers' ceramic patterns. It then recruited top managers from Shenzhen, one of the first areas in China to experiment with the market-economy, and encouraged its employees to obtain college education. Technical and marketing personnel were sent abroad for training and market research. The employees participated in the Confucian-style "devil training" classes (originated in Japan), focusing on the ideology of good team spirit, good health, and good eloquence.

In 1995, C\&C implemented a computer integrated manufacturing system (CIMS), under the Chinese government's "863 High-Tech Program", to improve its time to market, quality, cost and service processes. To reduce development time and broaden its technical base, $\mathrm{C} \& \mathrm{C}$ formed partnerships with universities, research institutes and other companies. The computerized system integrated sales, production, purchasing, storage, accounting, and personnel functions, and supported collaborative team-based work among the workers, technologists, and managers. CIMS yielded a three-dimensional computer-aided designing capability for decorative ceramics. The customers could now participate directly in the design of new or customized ceramic products. Through rapid 3-D "virtual" prototyping, the cost and time to design, produce, and deliver a new prototype ceramic sample to the customer was dramatically cut.

In 1999, C\&C reached pinnacle of publicity, when the Great Hall of the People ordered 250 thousand pieces of ceramic products for the $50^{\text {th }}$ Anniversary of People's Republic of China. As a result, C\&C gained name as "China's First Brand in China". C\&C was now an undisputed leader in sales volume, market share, production, and 
design. In 2000, a new plan called for the "Projects of Two One Hundreds" - 100 specialty stores and 100 specialty counters in nationally known department stores and supermarkets, for reinforcing $\mathrm{C} \& \mathrm{C}$ 's premium image.

The growing position at home worked wonders in the global market also. Traditionally, C\&C had very limited sales in the lucrative international markets. Now, $\mathrm{C} \& \mathrm{C}$ launched a new plan that offered manufacturing services to the overseas companies under their own brands. Its sales pitch was, "Why do you make your own products when I can provide the exact goods with better quality for almost half of your price?" C\&C rapidly secured outsourcing contracts from several large foreign ceramic makers, including in the US. By the end of $2000,70 \%$ of the sales came from the international markets, spread across more than 20 countries.

Summarizing the ingredients of transformation, CEO Zhang observed: "So, I have all of them: the best in ceramic design, the best in furnace, the best in mould, and the best in product pattern and decoration. Had it not been for these people with the skills and experiences that were passed down for thousands of years in ceramic operation, $\mathrm{C} \& \mathrm{C}$ would not have made such brilliant success today."

At the time of forming the joint venture in 1993, C\&C had three goals: to be first in China, then to be first in Asia, and finally to be first in the world. In 1998, C\&C became a leader in China, when its domestic sales reached 61.5 million yuan, up from 27 million yuan in 1995. In 1999, it gained leadership in Asia, when its exports revenue reached 115 million yuan, up from 30 million yuan in 1995. Now, C\&C, with 30 million pieces of supreme ceramics earning 180 million yuan of revenues, was eyeing at becoming a global leader by the end of 2005 with an output of 80 million pieces.

\subsubsection{Summary}

C\&C began its revival, despite all odds and lack of technological capability, based on one crucial asset: its deep links with the government. Despite rejection from the banks, it obtained initial restructuring funding from the special government reserves, and established a joint venture with a Hong Kong-based ceramics group. The partner helped C\&C identify not just appropriate world-class technology, but also co-specialized production formula, precustomized to Chinese raw materials and top quality standards, and complementary design patterns, from Germany. $\mathrm{C} \& \mathrm{C}$ then obtained preferential state-loans for CIMS. The computerization of the design process, and its integration with all other functions, allowed $\mathrm{C} \& \mathrm{C}$ to bring in customers and employees in the designing process, and thus gain from the age-old cultural knowledge of the Chinese people in ceramics making. Having built domestic reputation as a top-end brand, it used this image as a platform for securing contracts from the foreign firms of manufacturing ceramics. C\&C's strategic business model is typical of the Chinese firms seeking to globalize - they tend to rely on the foreign partner and on initial success in the Chinese market, while making full use of the incentives offered by the government. Therefore, it suggests that a firm with cultural embeddedness, and low technological capability, will gravitate towards "Divergence" or home-based business model.

\subsection{Case II: Huajing - High Cultural Embeddedness, High Technological Capability}

Huajing, a leading state-owned microelectronics group in China, was founded in 1989 through merger of a state-owned research institute with a state-owned microelectronics factory. From the outset, Huajing was the darling of the Chinese government, media, and people. It was a vertically integrated enterprise, engaged in the development, manufacturing, and marketing of two major lines of semiconductors: Discrete Devices and Integrated Circuits. As a typical state-owned enterprise, Huajing was a "small society" engaged in several social operations, such as day care, hospital, and child education. More than 2,000 customers were served in China, which included many top ranked and most profitable of China's electronics enterprises, and several others in Asia-Pacific and South America. Huajing employed over 450 qualified researchers and had cooperative technology development alliances with other firms in the industry and with several universities and research institutes. Nearly all its technical staff had training from internationally renowned firms, including Toshiba of Japan and Siemens of Germany as part of technology transfer deals. Huajing received several national and provincial level prizes for advancement in science and technology, and was the first to introduce several key semiconductor technologies, such as $64 \mathrm{~K}$ and $256 \mathrm{~K}$ DRAM, in China. 
Under the $\$ 2$ billion Project 908 of China's $8^{\text {th }}$ Five-Year Plan (1990-95), Huajing was authorized to build a super-large integrated circuit production line using equipment from Lucent Technologies. However by the time the plant was ready for production, next generation technologies had entered the market, and many Chinese companies were acquiring competitive integrated circuit technologies from Taiwanese firms at a 40-50\% discount. Huajing's plant achieved low production volumes ( $7 \%$ of capacity), and incurred heavy losses. With a 1 billion yuan debt, Huajing could hardly pay even wages during the 1998 Asian financial crises.

As a first step towards restructuring, Huajing convinced the federal government to transfer its ownership to the local Wuxi municipality. Wuxi municipality, with 59\% equity in Huajing, assigned Hi-Tech Industrial Park status to the location around Huajing's plant. The Park offered fiscal and operational incentives and took over Huajing's social units, thereby generating annual savings of 3.4 million yuan. The creditor banks, whose debt to Huajing was converted into stock, held the rest $41 \%$ equity. Thereafter, Huajing disaggregated the loss-incurring $\$ 2$ billion integrated circuit plant into separate design and fabrication (fab) units.

The design facilities were transferred to a new 10 million yuan fabless (i.e. standalone) subsidiary, with $55 \%$ of stock given to the employees as an incentive mechanism. In 1999, it marketed 57 new products, generating annual new product sales of 414 million units, worth 227 million yuan, with monthly profits of 1.5 million yuan.

The fab management was transferred to a Hong Kong-based Chinese American venture capital start-up, CSMC, on a profit sharing basis. CSMC invested 80 million yuan for investments in computers and process reengineering, and introduced a flexible manufacturing system, and offered customer service training to the employees. In August 1999, CSMC acquired 51\% equity in the fab, creating a US\$6 million joint venture. By 2000, the fab was making 70,000 wafers of 229 different integrated circuits, with more than $100 \%$ capacity utilization. It realized a monthly turnover of more than 30 million yuan, with net profits of 10 million yuan and a net profit margin of 33\%. Further, it had established strong links with many domestic and international design-house clients, and integrated device manufacturers.

The back-end package assembly units were transferred to another new subsidiary. Remaining operations related to discrete devices and silicon materials were put into the fourth subsidiary, identified as the group's cash cow, and a platform to generate quick returns and to build market position, since the market for its products was in a growth phase. The restructuring gradually builds up advantage in global markets and in higher-end products. The group revenue jumped from 4.3 billion yuan in 1998 to 8.2 billion yuan in 2000, and the profits also boomed.

\subsubsection{Summary}

In summary, Huajing enjoyed strong culturally embedded support from the government and media, and had great technological capability respected by all the clients, supported with long-term alliances with Toshiba (Japan), Siemens (Germany), and Lucent Technologies (USA) and an internal research unit. As it reeled under heavy indebtedness, Huajing convinced the central government to transfer its ownership to the local Wuxi municipality and restructured its debt into equity. The operations were disaggregated into four separate subsidiaries, following the value chain disintegration in the global as well as local markets. A separate strategy was developed for each business unit, depending on the available market opportunities and business capabilities. There was an overarching corporate vision of focusing growth first of the low-end units, and then building up the higher-end units, while not discounting the development of any of them either now or in future. On the whole, Huajing, with its strong cultural embeddedness and technological capability, did not follow a pre-existing logic. Rather, it developed a logic of its own, or "trans-vergence," for a distinct competitive advantage.

\section{Discussion \& Conclusions}

In this article, we presented two case studies. The case studies suggest that the nature of strategic business model is related to cultural embeddedness and technological capability. They indicated that when the firms lack technological capability, they might rely on their cultural embeddedness to gain competitive advantage ("divergence" model). On the other hand, when the firms enjoy both technological capability and cultural embeddedness, then they could discover varying emergent opportunities for gaining distinctive advantage ("transvergence" model). 
Several scholars believe that the emerging markets suffer from a cultural lag, and that the process of globalization forces them to choose between economic efficiency and cultural ties (Kerr et. al., 1964; Useem, 1996). Our analysis indicates the fallacy of this view. While globalization does expose the firms to a broader menu of cultural options, the firms can still use their cultural embeddedness for bringing fresh perspective and differentiated advantage to the established international strategic business models. The cultural embeddedness may help, for instance, in transforming the strong links with the government into weaker, more strategic links. It can also help in more effective codification of the tacit traditional know-how.

An implicit belief in the convergence-divergence debate is that the firms of a nation all move towards a single model - either convergence or divergence, or alternatively, cross-vergence. Our analysis suggests that different firms in a nation may evolve a different type of model, some convergent, some divergent, some crossvergent, and some could be transvergent - i.e. driven by the discovery of emergent market opportunities.

Notwithstanding its exploratory nature and reliance on cast studies, the study makes an important contributingon in understanding the influence of globalization on the strategic business models in an emerging market context. - It also suggests that the culture and technology may not be substitutes or opposing forces in the globalization process - both can work together in complementary ways, and/or facilitate discovery and creation of new organizational foundations for competitive advantage.

\section{References}

1. Abo, T. (1994). Hybrid Factory: The Japanese Production System in the United States. New York: Oxford University Press.

2. $\quad$ Albert S. \& Whetten, D.A. (1985). Organizational Identity. Research in Organizational Behavior. 7: 263295.

3. Brown, S. L. \& Eisenhardt, K. M. (1998). Competing on the Edge: Strategy as Structured Chaos. Boston, MA: Harvard Business School Press.

4. Child, J.D. (1981). "Culture, contingency and capitalism in the cross-national study of organizations". Research in organizational behavior. 3: 303-356.

5. England, G.W. \& Lee R. (1974). "The relationship between managerial values and managerial success in the United States, Japan, India, and Australia". Journal of Applied Psychology, 59, 411-419.

6. Glaister, K.W. \& Wang, Y. (1993). "UK joint ventures in China: motivation and partner selection". Marketing Intelligence \& Planning, 11: 9-15.

7. Goodstein L., Nolan T., Pfeiffer J. W. (1992). Applied Strategic Planning: How to Develop a Plan That Really Works. NY: McGraw-Hill.

8. Guillén M.F. (2000). “Corporate governance and globalization: Is there convergence across countries?" Advances in International Comparative Management. 13:175-204.

9. Guo, J-J (2001). A Comment on Reform of State-Owned Enterprises in China: Why "Grasp the Large and Set Free the Small". Taiwan: Taiwan Research Institute.

10. Hillebrand W., Messner D., \& Meyer-Stamer, J. (1994). "Strengthening technological capability in developing countries: Lessons from German Technical Cooperation." Working Paper \# 12/94, Berlin: German Development Institute.

11. Higgins, R.C. (1977). "How much growth can a firm afford?", Financial Management, 3: 3-16.

12. Hofstede, G. (1980). "Motivation, leadership, and organization: Do American theories apply abroad?". Organizational Dynamics, 9: 42-63.

13. Kerr, C., Dunlop, J. T., Harbison, F., \& Myers, C. A. (1964). Industrialism and Industrial Man. New York: Oxford University Press.

14. Laurent, A. (1983). "The cultural diversity of Western conceptions of management", International Studies of Management and Organization. 13: 75-96

15. Low, L. (2001). "Implications of Globalization for Poverty Reduction Efforts in Asia and the Pacific", Paper delivered at the Conference, Asia and Pacific Forum on Poverty: Reforming Policies and Institutions for Poverty Reduction, February. Manila: Asia Development Bank.

16. McGrath, R.G. \& Macmillan, I.C. (2000) The Entrepreneurial Mindset. MA: Harvard Business School 
Press.

17. Pascale, R. T. \& Maguire M. A. (1980). "Comparison of selected work factors in Japan and the United States", Human Relations, 33: 433-455.

18. Ralston, D.A., Gustafson, D.J., Cheung, F. \& Terpstra, R.H. (1993). "Differences in managerial values: A study of U.S., Hong Kong and PRC managers", Journal of International Business Studies, 24: 249-75.

19. Smith, A. (1776). An Inquiry into The Nature and Causes of the Wealth of Nations. London: Strahan and Cadell.

20. Suarez-Villa L. \& Rama R. (1996). "Outsourcing, R\&D, and the pattern of intra-metropolitan location: the electronics industries of Madrid", Urban Studies, 33(7): 1155-1197.

21. Sun (2002). "Organizational Development and Change in Chinese state owned enterprises: a human resource perspective", Leadership and Organization Development Journal, 21(8): 379-389.

22. Useem, M. (1996). Investor Capitalism: How Money Managers Are Changing the Face of Corporate America. New York: Basic Books. 